International Journal of Pharmaceutics \& Pharmacology

\title{
Advancements in Oral Medications to Treat Hepatitis C
}

Sabika Zaheer ${ }^{1}$, Hamna Nasar ${ }^{1}$, Sundus $^{l}$, Kanwal $^{1}$, Rayeesa Tanveer ${ }^{1}$, Abbas Ahmed $^{l}$, Abida Niazi $^{2}$, Abida Hussain ${ }^{3}$ and Faiza Naseer ${ }^{3 *}$

${ }^{1}$ Department of Pharmacy, Quaid-i-Azam University, Islamabad, Pakistan

${ }^{2}$ University of Veterinary and Animal Sciences, Lahore, Pakistan

${ }^{3}$ Department of Pharmacy, Government College University Faisalabad, Pakistan

Article info

Received 24 April 2018

Revised 23 May 2018

Published 28 May 2018

*Corresponding author: Faiza

Naseer, Department of Pharmacy,

Government College University

Faisalabad, Pakistan, E-mail:

Faiza.naseer@ymail.com

\begin{abstract}
Recent advancement made in oral treatment of Hepatitis $C$ shows a great improvement in number and types of drugs provided to physicians and pharmacists to decide for an intelligent treatment plan. This pharmacotherapy leads to more effective, better tolerable and shorten duration regimens. The new drugs approved by FDA are more reliable and safe than the previous ones, but as they are more selective for one or two genotypes, so this still provides a room for improvement and development in treatment options, for which continuous research is going on. Current review focuses on why the new drugs were introduced and how they were better than the preceding ones. The drugs discussed here are in chronological order of their discovery from 2014 to 2016, besides their comparison with each other. The studies of different researchers have contributed in the acknowledgement of mechanism of action, pharmacokinetics, pharmacodynamics, clinical behaviour and adverse events of these drugs. The importance of IV Interferons therapy switched to all-oral treatment. And the provision of guidelines for better treatment protocols.
\end{abstract}

Keywords: Oral therapy; advancement; HCV; Direct inhibitors; Indirect inhibitors

\section{Introduction}

About 185 million people in the world are infected with hepatitis $\mathrm{C}$ virus (HCV). Since the discovery of $\mathrm{HCV}$ in 1989 [1]. HCV is a single-stranded RNA virus belonging to the Flaviviridae family [2,3]. The major routes of transmission are intravenous (IV), blood transfusion, haemodialysis, organ transplantation and less frequently sexual intercourse. It is asymptomatic with common sign and symptoms such as feeling very tired, sore muscles, joint pain, fever, nausea or poor appetite, stomach pain and itchy skin, dark urine and jaundice. Six major genotypes (1-6) of HCV have been identified [4]. Many subtypes and genotype 7 has been recently discovered and they have varying geographical distribution. Genotypes 1, 2, 3 and 4 are distributed worldwide with Genotype 1 accounting for $46 \%$ and denominated in Australia Europe and Latin America. Genotype 3 is prevalent in Asia and Genotype 4 is found in the North Africa and Middle East [5].

The epidemiology of HCV demands its treatment for oral therapy prior to IV. In $2000 \mathrm{HCV}$ management included only interferon monotherapy which is based on sustained virology response of 15 percent after 48 weeks of therapy [6]. Combination of oral medications and new regimens for the treatment have provided effective, safe and reliable results. People infected with 
hepatitis $\mathrm{C}$ can be cured with antiviral medicines, but it only reduces the risk for death from cirrhosis and liver cancer. Research is going on for the development of vaccines for hepatitis $\mathrm{C}$.

\section{Pathophysiology}

The lifecycle of $\mathrm{HCV}$ is not completely understood due to the lack of a productive cell culture system. HCV majorly targets hepatocytes and B lymphocytes. Several times studies have been done but the mode of $\mathrm{HCV}$ entry is still unknown. Viral clearance is associated with the action of strong virus-specific responses by cytotoxic $\mathrm{T}$ lymphocytes and helper $\mathrm{T}$ cells.

However, the infection may persist because of weak CD4+ and CD8+ T-cell responses during acute infection. When chronic infection is established, HCV does not appear to be cytopathic. In most infected people, viremia persists and often leads to hepatic inflammation and fibrosis. Liver lesions may appear as a result of non-specific local immune responses. External factors, such as chronic alcohol consumption and viral co-infections may lead to cirrhosis. Patients with cirrhosis are at high risk of developing hepatocellular carcinoma.

Again, the role of $\mathrm{HCV}$ proteins in hepatocarcinogenesis is unknown. RNA-dependent RNA polymerase, an enzyme involved in $\mathrm{HCV}$ replication lacks proofreading and generates a large number of mutant viruses known as quasi species. These are a major challenge to immune-mediated control of $\mathrm{HCV}$ and may explain variable clinical course and the difficulties in vaccine development.

Therefore, further progress in understanding of $\mathrm{HCV}$ infection and pathogenesis is waiting for the advent of new model systems and technologies $[7,8]$.

\section{Classification on the basis of mechanism of action}

\section{Indirect acting Antiviral Drugs}

\section{Pegylated Interferon (PEG-IFN)}

Interferon are group of naturally occurring proteins released by host cells in response to pathogens e.g., virus, bacteria and parasites. They belong to the cytokines class of proteins which activates the defense immune system of the body to eradicate pathogen [9, 10].

\section{Ribavirin}

Ribavirin belongs to a class of antiviral medications called guanosine analogue. Although the true mechanism of RBV is not well defined due to limited data available. Four hypothesis have been proposed; (1) direct inhibition of HCV replication (2) inhibition of host Inosine Monophosphate Dehydrogenase enzyme, (3) induction of misincorporation of nucleotides by the viral RNA polymerase, leading to lethal mutagenesis and production of virus infertility, (4) alteration in $\mathrm{T}$ helper cytokine balance (Table 1) $[9,10]$.

Table 1: Drugs approved by FDA in recent years.

\begin{tabular}{|c|c|c|}
\hline Generic Name & $\begin{array}{c}\text { Brand } \\
\text { Name }\end{array}$ & $\begin{array}{c}\text { Year of } \\
\text { Approval }\end{array}$ \\
\hline Boceprevir & Victrelis & 2011 \\
\hline Telaprevir & Incivek & 2011 \\
\hline Simeprevir & Olysio & 2013 \\
\hline Sofosbuvir & Sovaldi & 2013 \\
\hline $\begin{array}{c}\text { Ledipasvir/ } \\
\text { Sofosbuvir }\end{array}$ & Harvoni & 2014 \\
\hline $\begin{array}{c}\text { Ombitasvir/ } \\
\text { Paritaprevir/ } \\
\text { Ritonavir/ } \\
\text { Dasabuvir }\end{array}$ & Viekira Pak & 2014 \\
\hline $\begin{array}{c}\text { Ombitasvir/ } \\
\text { Paritaprevir/ } \\
\text { Ritonavir }\end{array}$ & Technivie & 2015 \\
\hline Daclatasvir & Daklinza & 2015 \\
\hline $\begin{array}{c}\text { Elbasvir/ } \\
\text { Grazoprevir }\end{array}$ & Zepatier & 2016 \\
\hline $\begin{array}{c}\text { Sofosbuvir/ } \\
\text { Velpastasvir }\end{array}$ & Epculsa & 2016 \\
\hline
\end{tabular}

\section{Direct Acting Antiviral Drugs}

\section{NS5A-inhibitors}

Daclatasvir belongs to the class of drugs called direct acting antivirals (DAAS). It is an inhibitor of HCV nonstructural (ns5a) protein. This viral protein has an enzymatic activity that is responsible for HCV RNA replication and assembly. It blocks the enzymatic activity and inhibits hyper phosphorylation of NS5A that results in the inhibition of HCV RNA. Velpatsir, Elabasvir, Ombitasvir and Ledipas antivirals also follow the same mechanism $[6,8,11,12]$. 


\section{NS5B Inhibitors}

Sofosbuvir is a nucleotide analogue and a potent inhibitor of NS5B polymerase in HCV. It is the analogue of uridine and is a phosphormidate which is tri-phosphorylated with in the cell. It is activated by the hepatic enzymes. This analogue then imitates nucleotide and block polymerase which in turn inhibits HCV RNA synthesis. Dasabuvir is also a HCV NS5B polymerase inhibitor [13].

\section{NS3/4A Protease Inhibitors}

Simeprevir, Boceprevir, Telaprevir, Grazoprevir and Paritaprevir follows the mechanism which inhibits NS3/4A protease. The NS3 protease enzyme catalyses the post-transcriptional processing of proteins required for viral replication. And NS34A is a cofactor that accelerates this process.

Boceprevir and Telaprevir reduce viral replication by inhibiting this enzyme/cofactor complex. Inhibition of NS3 enzyme also restores virally suppressed IFN pathways that initiates many important endogenous antiviral mechanisms $[6,14]$.

\section{Pharmacokinetics}

\section{NS5A Inhibitors}

Elbasvir after administration showed peak concentration approximately in $3 \mathrm{~h}$. For Elbasvir steady state was achieved with-in $6 \mathrm{~h}$. It has high protein binding distributed in tissues. It is metabolized by P450 $3 \mathrm{~A} 4$ and its elimination half-life is $24 \mathrm{~h}$. Elbasvir is given in $50 \mathrm{mg}$ in combination with $100 \mathrm{mg}$ Grazoprevir OD. This combination when given with Ribavirin for 12-16 weeks depending on genotype showed better treatment results.

Recommended initial dose for Daclatasvir is $60 \mathrm{mg} / \mathrm{day}$ which can be reduced to $30 \mathrm{mg} /$ day according to conditions. DCV is given with SOF for 12 weeks with or without RBV in non-chronic patients with compensated cirrhosis and for 24 weeks for treatment of HCV genotype 3. DVC is metabolized through CYP 3A4 metabolism [6]. Viekira Pak is a combination of Ombitasvir $12.5 \mathrm{mg}$, Paritaprevir $75 \mathrm{mg}$, Ritonavir 50 mg packaged with Dasabuvir $250 \mathrm{mg}$ is taken twice daily with meal (Table 2) [11].

\section{NS5B Inhibitors}

SOF is effective orally as a single dose per day. It is metabolized in liver. Renal and hepatic impaired patients do not require any dose modification. T-max is $0.5-3 \mathrm{~h}$ and elimination half-life is 0.48 to $0.75 \mathrm{~h}$. 400 $\mathrm{mg}$ dose of SOF is considered most effective when given in combination with PEG-INF and Ribavirin for 12-24 weeks $[13,15]$.

Table 2: Direct and Indirect acting drugs along with their mechanism and activity.

\begin{tabular}{|c|c|c|}
\hline Drugs & Mechanism & Activity \\
\hline \multicolumn{3}{|c|}{ Indirect acting } \\
\hline PEG-INF & $\begin{array}{l}\text { Activate body } \\
\text { defence system to } \\
\text { eradicate pathogen }\end{array}$ & $\begin{array}{l}\text { All HCV } \\
\text { genotypes }\end{array}$ \\
\hline Ribavarin & $\begin{array}{l}\text { True mechanism is } \\
\text { not well defined }\end{array}$ & $\begin{array}{l}\text { All HCV } \\
\text { genotypes }\end{array}$ \\
\hline \multicolumn{3}{|c|}{ Direct acting } \\
\hline Sofosbuvir & NS5B inhibitor & $\begin{array}{l}\text { All HCV } \\
\text { genotypes }\end{array}$ \\
\hline Dasabuvir & NS5B inhibitor & $\begin{array}{l}\text { All HCV } \\
\text { genotypes }\end{array}$ \\
\hline Daclatasvir & NS5A inhibitor & $\begin{array}{l}\text { All HCV } \\
\text { genotypes }\end{array}$ \\
\hline Velpatsir & NS5A inhibitor & $\begin{array}{l}\text { All HCV } \\
\text { genotypes }\end{array}$ \\
\hline Elbasvir & NS5A inhibitor & $\begin{array}{l}\text { All HCV } \\
\text { genotypes }\end{array}$ \\
\hline Ledipasvir & NS5A inhibitor & $\begin{array}{l}\text { All HCV } \\
\text { genotypes }\end{array}$ \\
\hline Ombitasvir & NS5A inhibitor & $\begin{array}{l}\text { All HCV } \\
\text { genotypes }\end{array}$ \\
\hline Simeprevir & NS4A/3 inhibitor & $\begin{array}{l}\text { Genotypes 1a } \\
\text { and } 1 \mathrm{~b}\end{array}$ \\
\hline Boceprevir & NS4A/3 inhibitor & $\begin{array}{l}\text { Genotypes 1a } \\
\text { and } 1 \mathrm{~b}\end{array}$ \\
\hline Telapevir & NS4A/3 inhibitor & $\begin{array}{l}\text { Genotypes } 1 \mathrm{a} \\
\text { and } 1 \mathrm{~b}\end{array}$ \\
\hline Grazoprevir & NS4A/3 inhibitor & $\begin{array}{l}\text { Genotypes 1a } \\
\text { and } 1 \mathrm{~b}\end{array}$ \\
\hline Paritaprevir & NS4A/3 inhibitor & $\begin{array}{l}\text { Genotypes } 1 \mathrm{a} \\
\text { and } 1 \mathrm{~b}\end{array}$ \\
\hline
\end{tabular}

\section{NS3/4A Protease Inhibitors}

Simeprevir has long absorption phase. Its Cmax is $4-6 \mathrm{~h}$ after administration. The steady state is achieved after 7 days of OD dosing. It is both a substrate and inhibitor of P-glycoprotein. It is metabolized by CYP3A4 enzyme. If given in combination with Rifampicin $48 \%$ decrease in AUC and 31\% increase in Cmax is observed. It is eliminated through biliary secretion. After single dose of $200 \mathrm{mg} 91 \%$ was recovered in faeces and less than $1 \%$ in urine. Its elimination half-life in $\mathrm{HCV}$ infected 
patients is $41 \mathrm{~h}$ which is 3 to 4 times longer than in $\mathrm{HCV}$ uninfected population. It showed no clear PK/PD relationship $[16,17]$.

After oral administration Boceprevir is absorbed with a T-max of approx. $2 \mathrm{~h}$. Steady state is achieved after approximately 1 day of three times a day dosing. Food enhances absorption by up to $60 \%$ at a dosing regimen of $800 \mathrm{mg}$ tid. BCP is primarily metabolized by the aldoketo reductase-mediated pathway to inactive metabolites. It is also a substrate and an inhibitor of CYP3A enzyme. BCP has a mean plasma half-life of $3.4 \mathrm{~h}$ and it is eliminated in the urine $[14,18]$.

Telaprevir is a substrate of the efflux transporter P-gp. It is recommended to take Telaprevir with food as food increases its absorption. It is metabolized through hepatic pathways including hydrolysis, reduction and oxidative metabolism by CYP3A. It is also a strong inhibitor of the CYP3A4 enzyme. The plasma half-life of Telaprevir is 8 to $11 \mathrm{~h}$. It is primarily eliminated in the faeces.

Grazoprevir after administration show peak concentration approximately at $2 \mathrm{~h}$. For Grazoprevir steady state is achieved within $6 \mathrm{~h}$. It has high protein binding distribution in tissues. It is metabolized by P450 3A4 and the elimination half-life for Graziprevir is 31 h. $100 \mathrm{mg}$ of Grazoprevir is given OD in combination with $50 \mathrm{mg}$ of Elbasvir for improved results [6].

\section{Clinical Indications}

\section{NS5A-inhibitors}

DCV shows high potential antiviral activity against all $\mathrm{HCV}$ genotypes and shows synergistic antiviral activity in combination with SOF, NS3/4A inhibitors (Asunapravir, Danoprevir) or NS5B inhibitors (Beclabuvir). DCV is the first drug that demonstrated safety and efficacy in treating HCV genotype 3 without the need for co-administration of Peg-IFN and RBV.

DCV is given with SOF for 12 weeks with or without RBV in non-chronic patients with compensated cirrhosis and for 24 weeks for treatment of $\mathrm{HCV}$ genotype3. Velapatsir is used to treat $\mathrm{HCV}$ infection of genotype 1 and $7[12,19]$.

\section{NS5B-inhibitors}

SOF shows propitious effects against all genotypes of HCV [20].

\section{NS3/4A-inhibitors}

Simeprevir is a second generation NS3A4 protease inhibitor and is recently approved for the treatment of HCV genotype 1 in combination with Peg-INF and $\mathrm{RBV}$. Telaprevir is used in combination with peg-IFN $\alpha$ and $\mathrm{RBV}$, for the treatment of genotype 1 chronic hepatitis $\mathrm{C}(\mathrm{CHC})$ in adult patients with compensated liver disease, including cirrhosis, who are treatment naive or who have been previously treated with IFN based treatment, including all prior null responders, partial responders and relapsers $[16,17]$.

BCP is used in treatment of Chronic Hepatitis C (CHC) genotype 1 infection, in combination with peg-INF $\alpha$ and RBV in adult patients (older than 18 years age) with compensated liver disease, including cirrhosis, who are previously untreated or who have failed previous interferon and ribavirin therapy [14].

\section{Viekira Pak}

Viekira Pak is an oral new antiviral drug with fixed drug combination of Ombitasvir, Paritaprevir and Ritonavir packaged with Dasabuvir used to treat chronic HCV infection genotype 1 with compensated liver disease [11].

\section{Techinive}

It is an oral fixed combination drug containing Ombitasvir, Paritaprevir and Ritonavir used to treat chronic HCV genotype 4 infection in patients without cirrhosis [21].

\section{Adverse Effects}

\section{Indirect Acting Antivirals}

Common side effects shown by peg-IFN, which occur in almost half of all patients include fever, chills, headache, muscle aches, pain and malaise. These side effects may vary from mild to severe. Other important side effects that may occur at higher doses are fatigue, diarrhoea, nausea, vomiting, abdominal pain, joint aches, back pain, anorexia, dizziness, congestion, confusion, increased heart rate, low WBC RBC \& platelet count, increased liver enzymes and triglycerides, skin rashes, hair loss, cough, oedema, allergic or anaphylactic reactions. RBV has many common side effects but it has two major FDA black box warnings. One for its teratogenicity and embryocidal effects and the other for haemolytic anaemia $[9,10]$.

\section{Direct Acting Antivirals}




\section{NS5A-inhibitors}

DCV usually has common side effects like headache, fatigue, nausea, diarrhoea. Velpatsir has common side effects of nausea, headache, fatigue insomnia, irritability, cough pruritus, difficulty in concentration and naso-pharyngitis. Severe adverse events found in clinical trials were enteritis, abdominal pain, pneumonia, acute MI, food poisoning, autecholesystitis and rupture of ovarian cyst $[12,19]$.

Adverse drug events shown by Elbasvir includes headache, nausea, fatigue, decreased appetite, anaemia, pyrexia and elevation of ALT. Patient treated with this should have hepatic monitoring prior to and during treatment. Ledipasvir shows common side effects like fatigue, headache, nausea, and insomnia [6].

\section{NS5B-inhibitors}

SOF has good safety profile. No serious adverse events are observed with it. Dasabuvir causes weakness, nausea, insomnia, skin problems, anaemia, allergic reactions and an increase in levels of liver enzymes $[15,22]$.

\section{NS3/4A-inhibitors}

High exposure to Simeprevir is associated with an increase in the frequency of adverse reactions i.e., rash and photosensitivity. When given in combination with peg-INF and RBV major adverse drug reactions reported are rash, photosensitivity, pruritus and nausea. Other common side effects include fatigue, influenza like illness, pruritus, headache and nausea.

It increases the frequency and severity of hyperbilirubinemia. Adverse drug events of Grazoprevir includes headache, nausea, fatigue, decreased appetite, anaemia, pyrexia and elevation of ALT. Patient treated with this should have hepatic function monitoring prior to and during the treatment [16].

\section{Contraindications}

\section{Indirect Acting Antivirals}

Peg-INF is not recommended for genotypes 1, 2 and 4 and is occasionally used in genotype 3 . RBV should not be given with Zidovudine due to increased risk of anaemia and Didanosine due to mitochondrial toxicity. Also, RBV should not be used alone to treat Hepatitis C because of increased chances of severe adverse effects [9].

\section{Direct Acting Antivirals}

\section{NS5A-inhibitors}

DCV has a well-tolerated and excellent safety profile, especially when used in combination with SOF. But taking Amiodarine with Sofosbuvir leads to serious bradycardia, therefore co-administration of Amiodarone with Sofosbuvir, in combination with DCV is not recommended and is metabolized through CYP3A metabolism so it should not be given with strong inducers of this enzyme (Rifampin, Phenytoin, Carbamazepine); or strong CYP3A inhibitors(Clarithromycin).

However, it can be used with moderate CYP3A inducers (Dexamethasone, Naficillin). Caution and dose adjustment is required when used with HMG CoA reductase inhibitors (Digoxin) or when used with HIV/HCV co-infected patients due to pharmacokinetic interactions between drugs.

No adjustment is required when co-administered with opioids [8]. Elbasvir is contraindicated in patients with organic anion transporting polypeptides, IBI/3 inhibitors for example cyclosporine. It is also contraindicated with strong cytochrome P450 3A4 reducers, for example Rimapcin, Phenytoin, Carbamezapine [6].

\section{NS5B-nhibitors}

SOF is safe and effective with no major contraindications. Sofosbuvir has no clinically significant interaction observed with various drugs in studies, so no dose adjustments required along with other drugs [15].

\section{NS3/4A-inhibitors}

Grazoprevir is contraindicated in patients with organic anion transporting polypeptides and IBI/3 inhibitors for example Cyclosporine. It is also contraindicated with strong cytochrome P450 3A4 reducers, for example Rifampcin, Phenytoin, Carbamazepine. Caution is required when given with strong $\mathrm{P} 4503 \mathrm{~A} 4$ inhibitors [6].

\section{Viekira Pak}

This drug is contraindicated in patients with Hepatic Impairment. It is also contraindicated in patients taking drugs like CYP3A and CYP2C8 inducers (which reduce efficacy), CYP3A and CYP2C8 inhibitors (which increases the concentration of Dasabuvir and QT 
prolongation). If the Viekira Pak is used with RBV, contraindications of RBV should also be considered. It should be avoided in pregnancy. It is pregnancy category B drug and also not given to the men whose partners are pregnant. It is not safe for peads and nursing mothers. The concomitant use of Viekira with other drugs may lead to therapeutic failure, resistance against the drug and occurrence of adverse effects [11].

\section{Techinive}

It is not given in females taking Ethinylestradiol therapy i.e., contraceptives. Before the treatment of $\mathrm{HCV}$ Infection, women must stop the contraceptive therapy. It should not give to the patients with moderate or severe liver disease. Patients who do not tolerate RBV, Techinive alone can treat the infection. However, it is contraindicated with contraceptives. A wide range of drug interactions are seen with Techinive. Antiseizures, Rifampin, Carbamazepine and Phenobarbital (decrease the levels of Techinive). With Ergot derivatives there is an increased risk of ergot toxicity. When given with contraceptives, it causes liver damage and with Triazolam there is an increase sedation effect [21].

\section{Harvoni}

Ledipasvir and SOF both are substrates for drug transporters i.e. BCRP and P-gp. Femotidine and PPI decrease Lidopasvir concentration. Anticonvulsants and anti-mycobacterials induce P-gp and hence their coadministration with SOF and Lidopasvir lead to decrease their concentration. Lidopasvir can inhibit intestinal P-gp and BCRP. These two are not metabolized by Cytochrome p450 system [13].

\section{Zepatier}

Grazoprevir is contraindicated in patients with organic anion transporting polypeptides, IBI/3 inhibitors for example Cyclosporine. It is also contraindicated with strong cytochrome P450 3A4 reducers, for example Rifampicin, Phenytoin and Carbamazepine. Caution is required when given with strong P450 3A4 inhibitors (Ketoconazole and Ritonavir) [6].

\section{Discussion}

Until a few years ago there were only two drugs approved by FDA for the treatment of HCV. These were peg-IFN and RBV which do not show good treatment regimen because of their many adverse effects including influenza like symptoms, depression, cytopenia, haemolytic anaemia, fatigue and rash and other common side effects. They also have selectivity for specific genotypes, as INF were mostly used for genotype 3 and were not recommended for genotype 1, 2 and 4. Also INF are given IV so as the all-oral option for treatment become available their use has been reduced. Although RBV has a good drug profile but the only problem with it was that it cannot be given alone but given with other drugs. These drawbacks of INF and RBV led to the evolution of new drugs. And when they were given in combination with new drugs, they show excellent treatment regimens and most effective and safety profiles.

In 2011, Boceprevir and Telaprevir were introduced which were specific for genotype-1. But these could not be used alone. Even though when they are given individually in combination with peg-IFN and RBV the therapy was improved up to $40-60 \%$, but it had a complication of triple therapy. Also, with the evolution of IFN free regimen therapy in 2014 these drugs were no longer used.

In 2013, Simeprevir was introduced which was effective for genotype 1a, 1b, 2, 4, 5, 6 and has good safety profile because it is 1000 times less active towards 20 other human proteases than HCV NS3/A4. Another agent Sofosbuvir, is the most promising agent and has best safety profile, less interactions \& contraindications and shorter duration of treatment. Initially in 2013 Simeprevir was used in combination with IFN \& RBV but later in 2014 FDA approved its use in combination with SOF. This combination gained much acceptance both from physicians and patients and was used widely as it was all-oral therapy. But these drugs were very expensive.

In 2014, a new agent named Harvoni (a drug with fixed dose of Ledipasvir and SOF) was introduced for genotype-1 treatment and it was given as single therapy without any adjuvant. It eliminated the need for IFN weekly injections and RBV intolerance.

In December 2014, Viekira Pak was approved by FDA. Viekira Pak is given with or without RBV to treat chronic infection of genotype-1 with compensated cirrhosis but because of its multitargeted action its safety profile is low. It is also used in patients with HCV/HIV co-infection. But it has a clinical limitation for not be used in patients with decompensated cirrhosis. Moreover, new treatments were adopted to reduce financial burden on the patients.

In 2015, Technive was introduced which is the combination of Ombitasvir, Paritaprevir and Dasabuvir. 
It was the first all-oral interferon free treatment for genotype-4. The drugs included in Technivie are similar to the drugs in Viekira Pak used for HCV genotype 1, but the difference is the Viekira Pak is copackaged with Dasabuvir whereas Technivie is not. When given with RBV it assures $100 \%$ cure within 12 weeks of therapy but as its major adverse reaction is elevation in liver enzymes, so it does not show propitious effect in patients with cirrhosis.

Another drug was introduced in the same year 2015 is Daclatasvir. DCV has high anti-viral potency and clinical efficacy for all genotypes. When it is used in combination with ribavirin and PEG-INF $\alpha$ it showed $60-100 \%$ efficacy for genotype-1 and $100 \%$ for genotype- 4 as compared to PEG-INF and ribavirin combination. When, given in combination with SOF, the efficacy increased to more than $90 \%$ especially in genotype-1. The DCV/SOF dual combination has shown an SVR rate of $>90 \%$ in non-cirrhotic patients with genotype 3, while the triple DCV/SOF+RBV combination achieved SVR in $90 \%$ of genotype 3 even with advanced fibrosis or cirrhosis. Finally, DCV+ SOF combination has showed excellent efficacy in patients with decompensated liver disease and across all subpopulations post transplantation. It was the first drug that showed safety and efficacy in treating genotype 3 without the co-administration of INF and RBV.

The current literature and clinical evidence supports ZEPATIER (Elbasvir and Grazoprevir) combination as the first line therapy in patient with HCV genotype 1 and 4 but it shows virologic failure and reduced activity in the presence of NS5A and NS3 substitution. In June 2016, another combination has been introduced on the basis of clinical trials that was Epclusa (Sofosbuvir and Velpatsvir), it can be used in patients of $\mathrm{HCV}$ with history of cirrhosis and hepatocellular carcinoma. It shows great efficacy for genotype 2 and 3 . The rate of adverse events of this combination is lower than SOF and RBV. It shows high tolerability and high antiviral efficacy.

\section{Conclusion}

With the passage of time the treatment for Hepatitis C has been changing for betterment. For many years PegINFs and RBV were used for the treatment, but as for the inconvenience of IV INF and RBV nonmonotherapy led to the development of new drugs. Since 2014 all-oral treatment without the coadministration of IFNs gained much popularity among both medical staff and patients. These medications promise higher cure rates, shorter treatment times, and all-oral treatment regimens for $\mathrm{HCV}$ infected patients. Now there is a vast variety of medications available to treat Hepatitis than in past.

This provides the physician to select the most appropriate drug on the basis of HCV genotype, with or without cirrhosis (if mild compensated or severe decompensated), treatment- naive or treatmentexperienced, hepatic or renal impairment and other health conditions. In short, they ensure rational use of drugs. Combination of all previous and new drugs and multidose treatment regimen has shown satisfactory results and reduce death rates. However, the cost of the therapy and discovery of new genotypes and subtypes of HCV demands for new less costly and safe drugs with more efficacy and less adverse events. Therefore, there is still a huge room for new developments and discoveries.

\section{Acknowledgement}

The authors have no acknowledgements to report.

\section{Conflict of Interest}

The authors have no actual or potential conflicts of interest to report.

\section{Funding}

No support in the form of grants, equipment, and/or drugs were received in the conduct of this research.

\section{References}

1. Messina JP. Global distribution and prevalence of hepatitis C virus genotypes. Hepatology 2015; 61: 77-87.

2. Lindenbach BD, Rice CM. Unravelling hepatitis $\mathrm{C}$ virus replication from genome to function. Nature 2005; 436: 933-938.

3. Poenisch M, Bartenschlager R. New insights into structure and replication of the hepatitis $C$ virus and clinical implications; Seminars in liver disease. Thieme Medical Publishers 2010.

4. Lee SR. Evaluation of a new, rapid test for detecting HCV infection, suitable for use with blood or oral fluid. J Virol Methods 2011; 172: 27-31.

5. Gower E. Global epidemiology and genotype distribution of the hepatitis $\mathrm{C}$ virus infection. $\mathrm{J}$ Hepatol 2014; 61: S45-S57.

6. Bell AM. Elbasvir/grazoprevir: A review of the latest agent in the fight against hepatitis $\mathrm{C}$. Int $\mathbf{J}$ Hepatol 2016. 
7. Maticic M. Lichen planus in hepatitis $\mathrm{C}$ virus infection: an early marker that may save lives. Acta Dermatovenerol Alp Pannonica Adriat 2007; 16: 36.

8. Manns M. All-oral daclatasvir plus asunaprevir for hepatitis $\mathrm{C}$ virus genotype $1 \mathrm{~b}$ : A multinational, phase 3, multicohort study. Lancet 2014; 384: 15971605.

9. Chung RT. Mechanisms of action of interferon and ribavirin in chronic hepatitis C: Summary of a workshop. Hepatology 2008; 47: 306-320.

10. Pawlotsky JM. Hepatitis C virus: Standard of care treatment. Adv Pharmacol 2013; 67: 169-215.

11. Raedler LA. Viekira Pak (ombitasvir, paritaprevir, and ritonavir tablets; dasabuvir tablets): All-oral fixed combination approved for genotype 1 chronic hepatitis C infection. Am Health Drug Benefits 2015; 8: 142.

12. Manolakopoulos S. Safety and efficacy of daclatasvir in the management of patients with chronic hepatitis C. Ann Gastroenterol 2016; 29: 282.

13. Gritsenko D, Hughes G. Ledipasvir/Sofosbuvir (harvoni): Improving options for hepatitis $\mathrm{C}$ virus infection. Pharmacy Therapeutics 2015; 40: 256.

14. Wilby KJ. Review of boceprevir and telaprevir for the treatment of chronic hepatitis C. Canadian J Gastroenterol Hepatol 2012; 26: 205-210.
15. Bhatia HK. Sofosbuvir: A novel treatment option for chronic hepatitis $\mathrm{C}$ infection. J Pharmacol Pharmacotherapeut 2014; 5: 278-284.

16. Izquierdo L. Simeprevir for the treatment of hepatitis $\mathrm{C}$ virus infection. Pharmacogenomics Pers Med 2014; 7: 241.

17. Talwani R. Simeprevir: A macrocyclic HCV protease inhibitor. Drugs Today (Barc) 2013; 49: 769-779.

18. Foote BS, Spooner LM, Belliveau PP. Boceprevir: A protease inhibitor for the treatment of chronic hepatitis C. Annals Pharmacother 2011; 45: 10851093.

19. Bunchorntavakul C, Reddy K. Review article: The efficacy and safety of daclatasvir in the treatment of chronic hepatitis $\mathrm{C}$ virus infection. Aliment Pharmacol Ther 2015; 42: 258-272.

20. Bonaventura A, Montecucco F. Sofosbuvir/velpatasvir: A promising combination. World J Hepatol 2016; 8: 785.

21. Badri PS. Drug interactions with the direct-acting antiviral combination of ombitasvir and paritaprevir-ritonavir. Antimicrob Agents Chemother 2016; 60: 105-114.

22. Gentile I. A novel promising therapeutic option against hepatitis $C$ virus: An oral nucleotide NS5B polymerase inhibitor sofosbuvir. Curr Med Chem 2013; 20: 3733-3742.

This manuscript was peer-reviewed

Mode of Review: Single-blinded

Academic Editor: Dr. Ruqaiyah Khan

Copyright: (92018 Zaheer S, et al. This article is distributed under the terms of the Creative Commons Attribution 4.0 International License (http://creativecommons.org/licenses/by/4.0/), which permits unrestricted use, distribution, and reproduction in any medium, provided you give appropriate credit to the original author(s) and the source, provide a link to the Creative Commons license, and indicate if changes were made. 